\title{
COMPETÊNCIAS DE AUXILIARES E TÉCNICOS DE SAÚDE BUCAL E O VÍNCULO COM O SISTEMA ÚNICO DE SAÚDE
}

\author{
COMPETENCIES OF AIDES AND TECHNICIANS IN ORAL HEALTH AND THE TIES WITH THE \\ NATIONAL HEALTH SYSTEM
}

\section{COMPETENCIAS DE AUXILIARES Y TÉCNICOS DE SALUD BUCAL Y EL VÍNCULO CON EL SISTEMA ÚNICO DE SALUD}

\author{
Cristine Maria Warmling ${ }^{1}$ \\ Evelise Klein da Rosa ${ }^{2}$ \\ Luciane Maria Pezzato ${ }^{3}$ \\ Ramona Fernanda Ceriotti Toassi ${ }^{4}$
}

Resumo O estudo teve por objetivo descrever o perfil sociodemográfico, de trabalho e formação de auxiliares e técnicos em saúde bucal com atuação no estado do Rio Grande do Sul. Foram analisadas as informações relatadas por 255 auxiliares e técnicos de saúde bucal que participaram do Congresso Rio-Grandense de Odontologia realizado em 2010 e 2012. A pesquisa utilizou-se de um questionário escrito, estruturado e autoaplicável, organizado em três blocos temáticos com as seguintes categorias: identificação (sexo, idade, estado civil, estado/cidade, renda, habilitação, vínculo e inscrição conselho/sindicato), formação (estabelecimento, duração, incentivo/dificuldades de atualização/formação) e processo de trabalho (competências e atribuições profissionais). Os resultados encontrados demonstraram que diferenças no processo de trabalho entre os auxiliares e técnicos de saúde bucal determinadas pelo vínculo de trabalho com o Sistema Único de Saúde estavam concentradas nas atribuições das competências de promoção e prevenção de saúde. Também se verificou que as atribuições das competências de organização do ambiente de trabalho e de atendimento clínico de saúde bucal conferem maior identidade ao trabalho desses profissionais, independentemente do vínculo. $\mathrm{O}$ estudo alerta para a sobreposição das competências e atribuições realizadas pelos auxiliares e técnicos de saúde bucal.

Palavras-chave saúde bucal; competência profissional; recursos humanos; saúde da família.
Abstract The study aimed to describe the sociodemographic, labor, and training profile of aides and technicians in oral health working in the state of Rio Grande do Sul, Brazil. Information reported by 255 oral health aides and technicians who attended the Rio Grande do Sul Dental Congress in 2010 and 2012 was analyzed. The survey used a written, structured, and self-administered questionnaire, organized into three thematic blocks under these categories: identification (gender, age, marital status, state/city, income, license, ties and board/labor union registration), training (establishment, duration, incentive/difficulties in keeping updated/training) and work process (professional competencies and attributions). The results showed that work process differences between oral health aides and technicians, as determined by their working ties with the National Health System, were mostly in the health promotion and prevention competency attributions. It was also found that the attributions of the working environment organization and clinical care competencies in oral health provide greater identity to the work of these professionals, regardless of their ties. The study points to the overlapping of skills and duties performed by oral health aides and technicians.

Keywords oral health; professional competency; human resources; family health. 


\section{Introdução}

A lei federal n. 11.889, promulgada em 24 de dezembro de 2008, propôs-se a regulamentar o exercício das profissões de técnico em saúde bucal (TSB) e auxiliar em saúde bucal (ASB) no Brasil (Brasil, 2008). É um acontecimento que se destaca no processo de profissionalização desses trabalhadores. Anteriormente, apenas resoluções do Conselho Federal de Odontologia determinavam as atribuições que o TSB e o ASB poderiam realizar em seus ambientes de trabalho na saúde. Com a lei, as atribuições foram reeditadas revitalizando o debate a respeito do papel, inserção e processos de trabalho e formação desses trabalhadores (Conselho Federal de Odontologia, 2009).

Houve consenso inicial de que após a publicação da lei haveria "maior proteção técnica e ética para o exercício profissional" (Liñan e Bruno, 2007, p. 297) e que o impacto no processo de trabalho em saúde seria positivo, com aumento do acesso aos serviços odontológicos e incentivo ao caráter de trabalho em equipe na prática odontológica (Frazão e Narvai, 2011). Apesar da concordância quanto aos aspectos de aumento da legitimidade profissional advindos da lei, verificaram-se problemas perpetuados no documento legal no que se refere à limitação das competências e atribuições profissionais, principalmente com relação às atividades clínicas de responsabilidade do TSB (Sanglard-Oliveira et al., 2012; Zanetti, Oliveira e Mendonça, 2012).

Persistem no Brasil incompreensões, desconhecimento e pouco investimento no desenvolvimento da prática profissional dos trabalhadores de níveis fundamental e médio da saúde bucal. Investigações sobre seus processos de trabalho se fazem necessárias, especialmente diante dos efeitos dos investimentos da Política Nacional de Saúde Bucal (Brasil, 2004b) na incorporação dos auxiliares e técnicos de saúde bucal. Instrumentos de abrangência nacional para o acompanhamento dos perfis profissionais precisam ser elaborados e testados.

As questões apresentadas justificaram o estudo aqui exposto, que teve por objetivo descrever o perfil sociodemográfico, de trabalho e formação de auxiliares e técnicos em saúde bucal que atuam no estado do Rio Grande do Sul. Pretendeu-se comparar resultados encontrados e aspectos da metodologia empregada com outros estudos de abrangência nacional e internacional que também se detiveram em definir perfis profissionais de trabalhadores técnicos em odontologia. Ao se analisarem investigações sobre perfil de técnicos em odontologia, almejou-se contribuir com o debate nacional sobre a necessidade de incorporação e qualificação desses trabalhadores na atenção em saúde bucal no Sistema Único de Saúde (SUS). 


\section{Competências e atribuições para atuar no SUS}

A definição das competências e atribuições dos auxiliares e técnicos de saúde bucal é ponto de debate histórico para a profissão (Narvai, 1991). Ainda hoje persistem por parte dos cirurgiões-dentistas o medo e a disputa, alimentados pelo desconhecimento a respeito do processo de trabalho dos técnicos de saúde bucal (Esposti et al., 2012). O conflito entre dentistas e técnicos ilustra o grau em que se inter-relacionam a jurisdição de competências e os projetos profissionais (Adams, 2004).

De acordo com a Classificação Brasileira de Profissões (CBO) (Brasil, 2002), categorização instituída com a finalidade de uniformização da identificação das ocupações no mercado de trabalho, o TSB e o ASB, juntamente com o técnico e o auxiliar em laboratório de prótese dental, constituem a família de técnicos em odontologia. A CBO de 2002 traz a seguinte descrição do trabalho do TSB e do ASB: atuam em clínicas privadas e, majoritariamente, nos serviços odontológicos municipais, estaduais e federais, sob supervisão de cirurgiões-dentistas, em horários irregulares. Orientam a população e os pacientes sobre prevenção e tratamento das doenças bucais (Brasil, 2002).

A ampliação dos serviços públicos odontológicos foi impulsionada pelos processos de municipalização e descentralização ocorridos na implantação do SUS. A utilização de trabalhadores técnicos de níveis fundamental e médio para atuar na odontologia acompanhou esse processo, expandindo-se para diversas organizações públicas dos setores de saúde e de educação, em diferentes regiões do Brasil. Essa incorporação gerou sistemas de trabalho inovadores, decorrentes principalmente da aplicação de princípios ergonômicos ao processo de trabalho odontológico e da realização de ações de promoção e prevenção de doenças bucais (Narvai, 1997; Frazão, 1998, 1999).

Análises sobre a força de trabalho em saúde bucal no Brasil demonstram que o contingente de cirurgiões-dentistas brasileiros é extremamente qualificado - $25 \%$ possuem curso de especialização, superando índices de países como Estados Unidos, Reino Unido, Canadá, Alemanha e França (Morita, Haddad e Araújo, 2010). Não se pode dizer o mesmo com relação aos técnicos em odontologia, pois parcela considerável desses trabalhadores ainda necessita qualificar sua atuação (Hansen, 2002; Pezzato e Coco, 2004; Kovaleski, Boing e Freitas, 2005; Oliveira, 2007).

No Brasil, de modo geral, tem sido tímida a incorporação ao trabalho em saúde bucal de profissionais técnicos de níveis fundamental e médio. Ainda que devam ser consideradas diferenças regionais importantes, o TSB é pouco 
absorvido nos serviços odontológicos; quando isso ocorre, limita-se a exercer o papel destinado ao ASB. No entanto, convivemos com a herança histórica da recorrente inclusão do ASB sem qualificação específica para a execução de suas atribuições, mesmo com toda a capacidade de observação e decisão exigida desses profissionais, que participam de ações clínicas, preventivas e administrativas na prática odontológica. Parte dessa realidade é resultado do lento processo de regulamentação vivenciado pelos técnicos em odontologia no país (Quadro 1).

Quadro 1

Série histórica com a descrição do número de cirurgiões-dentistas, técnicos e auxiliares de saúde bucal do Brasil inscritos no Conselho Federal de Odontologia e número atual desses profissionais no estado do Rio Grande do Sul

\begin{tabular}{|c|c|c|c|c|c|c|}
\hline $\begin{array}{c}\text { Categoria/ } \\
\text { Período }\end{array}$ & $\begin{array}{c}\text { Março 1990 } \\
\text { Brasil }\end{array}$ & $\begin{array}{c}\text { Março 1995 } \\
\text { Brasil }\end{array}$ & $\begin{array}{c}\text { Abril 2000 } \\
\text { Brasil }\end{array}$ & $\begin{array}{c}\text { Junho 2008 } \\
\text { Brasil }\end{array}$ & $\begin{array}{c}\text { Agosto 2013 } \\
\text { Brasil }\end{array}$ & $\begin{array}{c}\text { Setembro 2013 } \\
\text { Estado/RS }\end{array}$ \\
\hline Cirurgião-dentista (CD) & 99.146 & 124.735 & 156.368 & 220.005 & 252.098 \\
Técnico em saúde bucal (TSB) & 1.193 & 2.626 & 3.857 & 7.843 & 16.536 \\
Auxiliar em saúde bucal (ASB) & 4.920 & 12.969 & 22.951 & 65.096 & 95.510 \\
Relação TSB/CD & 0,01 TSB/CD & 0,02 TSB/CD & 0,02 TSB/CD & 0,03 TSB/CD & 0,06 TSB/CD \\
Relação ASB/CD & 0,04 ASB/CD & $0,1 \mathrm{ASB} / \mathrm{CD}$ & $0,14 \mathrm{ASB} / \mathrm{CD}$ & $0,29 \mathrm{ASB} / \mathrm{CD}$ & $0,37 \mathrm{ASB} / \mathrm{CD}$ & $0,34 \mathrm{TSB} / \mathrm{CD}$ \\
\hline
\end{tabular}

Fonte: Conselho Federal de Odontologia (2014).

O trabalho odontológico é tradicionalmente orientado por uma racionalidade instrumental caracterizada pela compartimentalização e fragmentação do saber e divisão técnica do trabalho, centrado no cirurgião-dentista e nos seus procedimentos técnicos, mais raramente na produção de saúde. Nessa forma de atuar, toma-se a boca como órgão fragmentado e destituído de corpo (Warmling, Marzola e Botazzo, 2012). Esse modelo epistemológico tradicional da prática odontológica tem dificultado a inserção dos auxiliares e técnicos em saúde bucal e impossibilitado o trabalho em equipe. Há um reducionismo no potencial qualitativo e quantitativo do saber/fazer em saúde bucal (Pezzato, Coco e Bagnato, 2007).

Mudanças tecnológicas e de organização no mundo do trabalho impulsionam o deslocamento do conceito de qualificação profissional, predominante nas óticas tayloristas e fordistas, para o conceito de competência que funda novas bases para as relações de trabalho e de educação (Ramos, 2011). Compreendendo esse processo, o Ministério da Saúde, de forma inovadora no campo da gestão dos processos de trabalho e formação, organizou em 2003 um perfil de competências profissionais para os auxiliares e técnicos em saúde bucal. O objetivo desse instrumento foi fornecer subsídios às insti- 
tuições formadoras na construção de currículos estruturados no modelo por competências. Para a construção do perfil, produziu-se um consenso com as principais entidades profissionais e de saúde brasileiras (Brasil, 2004a). O perfil de competências é um documento que amplia a compreensão do trabalho dos auxiliares e técnicos em saúde bucal, principalmente com relação às suas responsabilidades para atuar no SUS.

O novo status jurídico das profissões dos técnicos odontológicos a partir da promulgação da lei n. 11.889 não impediu que persistissem limitações ao trabalho desses profissionais. A lei não significou ampliação do papel desses trabalhadores, e há aspectos dela que falham por não apresentarem com clareza e objetividade a atribuição referida (Zanetti, Oliveira e Mendonça, 2012).

Esparsas pesquisas brasileiras estudaram os processos de trabalho dos auxiliares e técnicos em saúde bucal. Grande parte delas se caracteriza por delineamentos quantitativos com o uso de questionários fechados, priorizando a definição de um perfil profissional. Algumas descrevem o processo de validação do questionário utilizado. Há um direcionamento comum nesses estudos, que é a descrição das características básicas dos trabalhadores: sexo, idade, nível de escolaridade, registro profissional, vínculo de trabalho, remuneração, carga horária de trabalho, cursos de atualização etc. Enfatizam em suas análises as atribuições desempenhadas pelos trabalhadores usando como parâmetro o rol de atividades definido pelo Conselho Federal de Odontologia. Dois estados se destacam: São Paulo e Minas Gerais (Frazão, 1998; Ribeiro, Fischer e Marques, 1999; Sbravati, Meneghin e Pereira, 1999; Queluz, 2005; Paranhos et al., 2008; Liñan, 2009; Bonan et al., 2009; Sanglard-Oliveira, 2011). Raros são os estudos que se ocupam de analisar características das competências e atribuições de trabalhadores segundo sua inserção no SUS (Frazão, 1998; Sanglard-Oliveira, 2011). Uma vertente de estudos que se tornou clássica para a contribuição da compreensão do trabalho dos auxiliares e técnicos em saúde bucal no país se utilizou da história sobre percursos de emergência e incorporação desses profissionais (Carvalho, 1998; Pezzato e Cocco, 2004). Os processos de formação também foram foco de pesquisas brasileiras (Machado, 1999; Sá, 2000; Hansen, 2002; Pezzato, 2001).

Ao contrário do Brasil, estudos internacionais têm realizado com mais constância e amplitude pesquisas que avaliam e monitoram o desempenho dos técnicos odontológicos. Normalmente envolvem comparações entre realidades de diferentes países (Gibbons, Corrigan e Newton, 2001; Johnson, 2009; Nash et al., 2008; Luciak-Donsberger e Eaton, 2009).

O contexto apresentado fundamenta a questão que orientou e justificou o desenvolvimento do artigo: quais seriam as diferenças e as semelhanças entre os processos de trabalho de auxiliares e técnicos em saúde bucal segundo o vínculo ou não com o SUS? 


\section{Percurso metodológico}

Neste estudo, com delineamento transversal e descritivo, foram coletadas e analisadas informações de 255 auxiliares e técnicos de saúde bucal que participaram do Congresso Rio-Grandense de Odontologia (Corig) realizado nos anos de 2010 e 2012. Em 2010, foram entrevistados 54 ASBs e 43 TSBs, totalizando 97 participantes. Em 2012, participaram 103 ASBs e 55 TSBs, correspondendo a 158 profissionais pesquisados.

A produção das informações ocorreu por meio da aplicação de um instrumento estruturado e autoaplicável. O questionário foi organizado em três blocos temáticos com as seguintes categorias: bloco I - Identificação: perguntas de caráter sociodemográfico - sexo, idade, estado civil, estado/cidade, renda, habilitação, vínculo e inscrição conselho/sindicato; bloco II - Formação: estabelecimento de ensino, duração do curso, incentivo/dificuldades de atualização/formação; bloco III - Processo de trabalho: competências e atribuições profissionais que foram construídas a partir do Perfil de Competências do TSB elaborado pelo Ministério da Saúde (Brasil, 2004a). Os dados obtidos foram digitados em um banco de dados criado no Excel e posteriormente importados para o Programa Statistical Package for the Social Sciences (SPSS) para Windows, versão 16.0, e submetidos à análise descritiva.

A pesquisa foi submetida à Comissão de Pesquisa da Faculdade de Odontologia da Universidade Federal do Rio Grande do Sul (UFRGS) e ao Comitê de Ética em Pesquisa da UFRGS (CAAE n. 20626613.6.0000.5347). Previamente ao preenchimento dos questionários, todos os participantes assinaram o termo de consentimento livre e esclarecido, concordando com sua participação no estudo.

\section{Agir profissional e o vínculo com o SUS}

Os resultados encontrados consideraram as respostas dos auxiliares e técnicos que participaram da pesquisa e são apresentados e discutidos a seguir, segundo as categorias estudadas.

\section{Perfil demográfico}

Dos 255 participantes do estudo, a maioria $(61,6 \%)$ era de ASBs e mulheres $(96,5 \%)$. A idade variou entre 17 e 60 anos; 53,1\% tinham de 21 a 35 anos, $49,4 \%$ estavam solteiros e 80,8\% residiam no estado do Rio Grande do Sul, principalmente no interior $(50,6 \%)$.

O processo de marcante feminização da profissão que os resultados do estudo demonstraram é uma característica já descrita pela maioria dos estudos 
sobre perfil profissional de auxiliares e técnicos, tanto no Brasil (Frazão, 1998; Ribeiro, Fischer e Marques, 1999; Queluz, 2005; Oliveira, 2007; Bonan et al., 2009; Oliveira et al., 2009) como no cenário internacional (Gibbons, Corrigan e Newton, 2001; Ross, Ibbetson e Turner, 2007).

\section{Situação de trabalho}

Quanto à atuação profissional, 46,3\% dos ASBs e TSBs estudados relataram ter algum vínculo com o SUS, o qual foi exclusivo para $45,1 \%$ dos entrevistados. A atuação em clínicas privadas e consultórios particulares foi um pouco mais frequente, observada em $49,7 \%$ da população estudada. Foi relatado vínculo trabalhista pelas normas da Consolidação das Leis de Trabalho (CLT) por mais de 62,9\% da amostra, enquanto apenas $23 \%$ relataram ter seu vínculo assegurado por regime estatutário. Para 50,2\% dos ASBs e TSBs, a renda pessoal mensal variou de $\mathrm{R} \$ 510,00$ a $\mathrm{R} \$ 1.020,00$.

Outros estudos brasileiros sobre perfil profissional também analisaram a origem do vínculo trabalhista público ou privado. Essa representação parece influenciada pelo modo como a metodologia de coleta de informações define a população que deve participar dos estudos. Ribeiro, Fischer e Marques (1999) estudaram o perfil dos técnicos de higiene dental no estado de Minas Gerais, e a coleta de informações ocorreu por meio do envio de questionários para os municípios e em cursos promovidos pelo Conselho Regional de Odontologia (CRO) do estado. Encontraram predominância de vínculo com os serviços públicos. Já Queluz (2005) estudou o perfil das auxiliares de consultório dentário e técnicas de higiene dental no estado de São Paulo, entrevistando os profissionais apenas em grandes congressos odontológicos promovidos no estado. Encontrou predominância do vínculo privado. A amostra de egressos da escola no município de Montes Claros, em Minas Gerais, analisada por Bonan e colaboradores (2009), atuava predominantemente no serviço público.

Com relação à inscrição no CRO, 86,6\% dos participantes relataram dispor dela. Resultados similares a esse foram encontrados por Queluz (2005). Porém, apenas um pouco mais da metade da amostra total das participantes $(55,6 \%)$ obteve a inscrição no CRO por meio de formação profissional e 13,7\% através de carta de indicação do dentista, sendo que $11,7 \%$ referiram não possuir inscrição.

Quanto à filiação em sindicatos, 60,8\% dos participantes da pesquisa afirmaram não estar filiados no momento da realização da pesquisa. Um estudo de técnicos de higiene dental do Reino Unido observou algo parecido: somente $33 \%$ da amostra estudada apresentou registro na associação dos técnicos dentais do país, sugerindo que um número significativo deles não considerava isso necessário ou benéfico (Ross e Ibbetson, 2005). 


\section{Formação profissional}

Não há convergência significativa nas respostas dos participantes quando indagados sobre o estabelecimento de ensino onde realizaram o curso de formação. Três escolas apareceram apontadas com mais frequência: duas são estabelecimentos privados e uma delas é pública, mas já não realiza há mais de dez anos a formação de ASB e TSB. Sobre a carga horária total da formação, a inconsistência das respostas apresentadas é ainda maior, variando de cem até duas mil horas.

O modo de acesso à qualificação profissional referido pelos participantes foi com mais frequência a participação em congressos $(65,4 \%)$, seguida de cursos fora da instituição $(30,9 \%)$ e reuniões no local de trabalho $(24,7 \%)$. As dificuldades mais relatadas para se qualificarem relacionam-se a distância $(21,5 \%)$, falta de divulgação $(20 \%)$, custo $(18,4 \%)$ e falta de tempo $(14,1 \%)$. Menos de um terço dos participantes da pesquisa (36,4\%) assinalou não encontrar dificuldade para se qualificar.

O tema do acesso à qualificação profissional de técnicos odontológicos é abordado por vários estudos internacionais. No Reino Unido, higienistas dentais que responderam a um questionário de pesquisa aludiram que consideravam como formação permanente a leitura de jornais profissionais da área (Gibbons, Corrigan e Newton, 2001). Na Escócia, um inquérito com higienistas dentais demonstrou que a ausência de financiamento foi apontada como dificuldade para a realização de suas atividades de qualificação por $41 \%$ dos entrevistados, e $73 \%$ dos higienistas dentais pesquisados solicitaram maior acesso à qualificação por meio do ensino a distância, especialmente os que residiam em áreas rurais (Ross, Ibbetson e Rennie, 2005). Outro estudo no Reino Unido analisou as necessidades educacionais de higienistas dentais ressaltando um número de problemas reais e potenciais nesse campo. O acesso à educação foi destacado como problemático por $68 \%$, e $64 \%$ dos entrevistados relataram se sentir desatualizados (Ross e Ibbetson, 2005). Ross, Ibbetson e Turner (2007) verificaram que os higienistas dentais do Reino Unido que realizaram a qualificação profissional apresentavam vantagens em relação aos profissionais que não a possuíam, tais como maior número de procedimentos e de pacientes atendidos, além de maior tempo de permanência no emprego.

\section{Atribuições e competências profissionais}

Para a análise das competências e atribuições profissionais dos auxiliares e técnicos em saúde bucal, a amostra dos profissionais foi dividida em grupos de acordo com a existência ou não de vínculo de trabalho com o SUS. As quatro competências estudadas ('Promoção de saúde e prevenção de agravos'; 
'Prevenção e controle das doenças bucais'; 'Organização do ambiente de trabalho'; e 'Atendimento clínico em saúde bucal') foram analisadas por meio dos respectivos conjuntos de atribuições vinculadas a cada uma delas e apresentadas no questionário estruturado para que os profissionais pudessem escolher quais realizavam.

O cálculo da média de atribuições em cada competência apresentado na Tabela 1 foi obtido pela divisão entre o número total de atribuições assinaladas por competência e o número total de participantes segundo a categoria profissional vinculada ou não ao SUS. As médias do número de atribuições assinaladas em cada competência foram obtidas com o objetivo de compará-las segundo a categoria profissional (ASB e TSB) e vínculo ao SUS (SUS e não SUS) do participante da pesquisa. Esse tipo de procedimento para dimensionar o escopo da prática profissional foi usado por Johnson (2009).

Verificou-se que os auxiliares e técnicos do SUS responderam um pouco mais ao questionário em relação ao grupo Não SUS (percentual 12,7\% superior). No grupo dos trabalhadores do SUS, houve uma distribuição mais equânime dos resultados entre as quatro competências estudadas, comparando com os profissionais que não atuam no SUS. As competências menos referidas para ambos os grupos foram as que se relacionam a 'promoção e prevenção de agravos de saúde', e as mais referidas dizem respeito à 'organização do ambiente de trabalho e ao atendimento clínico em saúde bucal' . Porém, comparando os grupos, as competências de promoção e prevenção são mais reconhecidas pelos trabalhadores com vínculo ao SUS. Já as competências de 'organização do ambiente de trabalho e de atendimento clínico' são bem referidas por ambos os grupos, com uma pequena margem superior para os trabalhadores sem vínculo com o SUS (Tabela 1).

Tabela 1

Distribuição das competências e atribuições profissionais, em número absoluto e média, referidas pelos auxiliares e técnicos de saúde bucal de acordo com o vínculo ou não com o SUS, Rio Grande do Sul, 2010 e 2012

\begin{tabular}{|c|c|c|c|c|}
\hline Vínculo de trabalho & $65 \mathrm{ASBs} / \mathrm{SUS}$ & $50 \mathrm{TSBs} / \mathrm{SUS}$ & 83 ASBs/Ñ-SUS & $44 \mathrm{TSBs} / \tilde{N}-\mathrm{SUS}$ \\
\hline Competências e atribuições & $\mathrm{n}(\overline{\mathrm{X}})$ & $\mathrm{n}(\overline{\mathrm{X}})$ & $\mathrm{n}(\overline{\mathrm{X}})$ & $n(\bar{X})$ \\
\hline Promoção de saúde e prevenção de agravos & $270(4)$ & $253(4,8)$ & $71(0,7)$ & $33(0,7)$ \\
\hline Prevenção e controle das doenças bucais & $166(2,4)$ & $166(3,1)$ & $78(0,8)$ & $59(1,2)$ \\
\hline Organização do ambiente de trabalho & $409(6,1)$ & $316(6,0)$ & $502(5,5)$ & $271(5,8)$ \\
\hline Atendimento clínico em saúde bucal & $177(2,6)$ & $254(4,8)$ & $316(3,4)$ & $230(5,0)$ \\
\hline Total & $1.022(15,7)$ & $989(19,8)$ & $967(11,6)$ & $593(13,5)$ \\
\hline
\end{tabular}

Fonte: Dados de pesquisa elaborada pelas autoras.

Nota 1: A média de atribuições por competências foi calculada dividindo-se o número total de atribuições assinaladas em cada competência pelo número de profissionais da amostra segundo vínculo e categoria (ASB e TSB) que assinalaram.

Nota 2:TSB - técnico em saúde bucal; ASB - auxiliar em saúde bucal; SUS - Sistema Único de Saúde; Ñ-SUS - não SUS. 
Análises comparativas das médias de atribuições assinaladas em cada competência por auxiliares e técnicos com o mesmo vínculo de trabalho (SUS ou não SUS) demonstraram não haver diferenças significativas nas práticas de trabalho entre as categorias profissionais, pois as médias tendem a se aproximar independentemente do vínculo analisado. A competência de 'atendimento clínico em saúde bucal' apresentou uma pequena margem superior da média de frequência de atribuições assinaladas do TSB em relação ao ASB - o que se repetiu independentemente do tipo de vínculo. Porém, pareceu pequena a vantagem, tendo em vista ser essa a competência que contém atribuições de responsabilidade legal exclusivas do TSB.

São resultados que vão ao encontro do que recentemente demonstrou Sanglard-Oliveira (2011) ao analisar o trabalho do TSB vinculado à Estratégia Saúde da Família do SUS: uma atuação que enfatiza atividades educativas e preventivas e, em menor intensidade, a realização das atribuições clínicas e assistenciais. E com viés diferente do que encontrou o inquérito realizado com higienistas dentais no Reino Unido, em que a maior proporção dos entrevistados identificou-se com responsabilidades na área da clínica, e pouco mais de um terço apontou seu papel em atividades na área de educação em saúde bucal. Outros papéis incluindo práticas administrativas e de pesquisa foram nesse estudo muito menos comumente identificadas (Gibbons, Corrigan e Newton, 2001).

\section{Ações de promoção de saúde e prevenção de agravos}

Das atribuições que compõem a competência denominada ações de promoção de saúde e prevenção de agravos, três são bem referidas para ambos os grupos de trabalhadores estudados (SUS e não SUS): 'participar de reuniões de equipe', 'contribuir no plano de ações da equipe' e 'interagir com outros setores em ações de promoção de saúde'. Porém, atividades com enfoque comunitário atingiram frequências elevadas apenas para auxiliares e técnicos do SUS $-61,9 \%$ referiram 'realizar atividades com a comunidade', 43,2\% 'realizar visitas domiciliares' e 42,4\% 'contribuir na realização de levantamentos epidemiológicos' (Tabela 2). 
Tabela 2

Distribuição das competências e atribuições profissionais referidas pelos auxiliares e técnicos de saúde bucal de acordo com o vínculo ou não com o SUS, Rio Grande do Sul, 2010 e 2012

\begin{tabular}{|c|c|c|}
\hline Competências e atribuições & $\begin{array}{l}118 \text { ASBs/TSBs SUS } \\
\text { n (\%) }\end{array}$ & $\begin{array}{l}127 \text { ASBs/TSBs Ñ-SUS } \\
\text { n (\%) }\end{array}$ \\
\hline \multicolumn{3}{|l|}{ Promoção de saúde e prevenção de agravos } \\
\hline Atua no cuidado de moradores e famílias no ambiente domiciliar & $36(30,5)$ & $9(7,1)$ \\
\hline Participa de atividades na comunidade & $73(61,9)$ & $8(6,3)$ \\
\hline Realiza visitas domiciliares & $51(43,2)$ & $3(2,4)$ \\
\hline Realiza levantamento de necessidades de saúde bucal da comunidade & $44(37,3)$ & $4(3,1)$ \\
\hline Contribui na realização de levantamentos epidemiológicos & $50(42,4)$ & $4(3,1)$ \\
\hline Participa de reuniões de equipe & $92(77,9)$ & $27(21,2)$ \\
\hline Contribui no plano de ações da equipe & $68(57,6)$ & $21(16,5)$ \\
\hline Avalia e reprograma ações definidas pela equipe & $29(24,6)$ & $6(4,7)$ \\
\hline Organiza grupos de discussão & $22(18,6)$ & $3(2,4)$ \\
\hline Interage com outros setores em ações de promoção da saúde & $58(49,1)$ & $19(15,0)$ \\
\hline \multicolumn{3}{|l|}{ Prevenção e controle das doenças bucais } \\
\hline Reconhece doenças bucais e encaminha para o atendimento clínico & $48(48,6)$ & $35(27,5)$ \\
\hline Utiliza recursos de comunicação para educação em saúde bucal & $70(59,3)$ & $36(28,3)$ \\
\hline Organiza e executa atividades de fluorterapia & $63(53,3)$ & $15(11,8)$ \\
\hline Organiza e executa atividades de higiene bucal supervisionada & $94(79,6)$ & $41(32,2)$ \\
\hline Orienta quanto ao câncer bucal & $57(48,3)$ & $10(7,9)$ \\
\hline \multicolumn{3}{|l|}{ Organização do ambiente de trabalho } \\
\hline Adota medidas para se proteger dos riscos do trabalho odontológico & $101(85,5)$ & $102(80,3)$ \\
\hline $\begin{array}{l}\text { Aplica medidas de segurança no armazenamento, transporte, manuseio e } \\
\text { descarte de produtos e resíduos odontológicos }\end{array}$ & $95(80,5)$ & $105(82,6)$ \\
\hline Realiza controle de infecção em odontologia & $85(72,0)$ & $86(67,7)$ \\
\hline Trabalha em equipe & $105(88,9)$ & $85(66,9)$ \\
\hline Recepciona e acolhe o paciente & $103(87,2)$ & $106(83,4)$ \\
\hline Marca consultas & $98(83,0)$ & $91(71,6)$ \\
\hline Organiza o arquivo/fichário & $87(73,7)$ & $81(63,7)$ \\
\hline Controla o movimento financeiro & $5(4,2)$ & $52(40,9)$ \\
\hline Utiliza recursos de informática & $46(38,9)$ & $65(51,1)$ \\
\hline \multicolumn{3}{|l|}{ Atendimento clínico em saúde bucal } \\
\hline Manipula materiais de uso odontológico & $104(88,1)$ & $104(81,8)$ \\
\hline Instrumenta os profissionais nas intervenções clínicas & $100(84,7)$ & $106(83,4)$ \\
\hline Processa o filme radiográfico & $23(19,4)$ & $80(62,9)$ \\
\hline Confecciona modelos de gesso & $9(7,6)$ & $86(67,7)$ \\
\hline Realiza controle de placa bacteriana & $71(60,1)$ & $22(17,3)$ \\
\hline Remove suturas & $47(39,8)$ & $36(28,3)$ \\
\hline Remove cálculo supragengival & $30(25,4)$ & $20(15,7)$ \\
\hline Realiza tomadas radiográficas de uso odontológico & $14(11,8)$ & $28(22,0)$ \\
\hline Realiza moldagens & $2(1,6)$ & $29(22,8)$ \\
\hline Aplica selantes & $14(11,8)$ & $2(1,5)$ \\
\hline
\end{tabular}


Continuação - Tabela 2

Distribuição das competências e atribuições profissionais referidas pelos auxiliares e técnicos de saúde bucal de acordo com o vínculo ou não com o SUS, Rio Grande do Sul, 2010 e 2012

\begin{tabular}{lcc}
\hline \multicolumn{1}{c}{ Competências e atribuições } & $\begin{array}{c}\text { 118 ASBs/TSBs SUS } \\
\mathbf{n}(\%)\end{array}$ & $\begin{array}{c}127 \text { ASBs/TSBs Ñ-SUS } \\
\mathbf{n}(\%)\end{array}$ \\
\hline $\begin{array}{l}\text { Atendimento clínico em saúde bucal } \\
\text { Insere e distribui material restaurador na cavidade dentária }\end{array}$ & $9(7,6)$ & $4(3,1)$ \\
Troca fios, elásticos e procedimentos ortodônticos & 0 & $12(9,4)$ \\
Realiza o isolamento absoluto & $3(2,5)$ & $7(5,5)$ \\
Troca brackets, bandas e outros aparelhos ortodônticos & 0 & $8(6,2)$ \\
Realiza testes de vitalidade pulpar & $5(4,2)$ & $2(1,5)$ \\
\hline
\end{tabular}

Fonte: Dados de pesquisa elaborada pelas autoras.

Nota:TSB - técnico em saúde bucal; ASB - auxiliar em saúde bucal; SUS - Sistema Único de Saúde; Ñ-SUS - não SUS

\section{Ações de prevenção e controle das doenças bucais}

Comparando os grupos SUS e não SUS quanto ao perfil da competência ações de prevenção e controle das doenças bucais, duas atribuições foram mais referidas em ambos, mas com frequências maiores para os trabalhadores do SUS. Grande parte $(79,6 \%)$ dos trabalhadores do SUS referiu 'organizar e executar atividades de higiene bucal supervisionada', enquanto apenas $32,2 \%$ dos que não atuam no SUS afirmaram ser essa atribuição parte de sua competência. 'Utilizar recursos de comunicação para educação em saúde bucal' foi referido como atribuição para 59,3\% dos trabalhadores do SUS e $28,3 \%$ para os Não SUS (Tabela 2).

Os achados do estudo sobre o perfil das competências de promoção de saúde e prevenção de doenças segundo o vínculo ou não com o SUS são corroborados pelos estudos brasileiros, que também demonstraram um índice elevado de relatos dessas atribuições por profissionais que atuavam vinculados ao SUS (Frazão, 1998; Sanglard-Oliveira, 2011). Por sua vez, Queluz (2005) demonstrou que as atividades educativas não atingiam índices elevados em uma amostra de trabalhadores predominantemente vinculada aos consultórios privados.

Os trabalhadores do SUS demonstraram índices similares próximos a 50\% nas outras três atribuições também relacionadas ao escopo da competência de prevenção e controle de doenças, que se referem ao encaminhamento para atendimento, fluorterapia e orientação sobre o câncer bucal. Já os trabalhadores não SUS atingiram índices bem inferiores para essas atribuições, destacando-se que nem 10\% desses auxiliares e técnicos realizam a 'orientação quanto ao câncer bucal' (Tabela 2). 
Oliveira e colaboradores (2009), em estudo que investigou o conhecimento e atuação sobre o câncer bucal de auxiliares e técnicos vinculados ao SUS, verificaram que, apesar de os trabalhadores terem conhecimentos sobre os fatores de risco, relataram sentir necessidade de treinamento específico para a realização de atividades de prevenção do câncer bucal.

\section{Organização do ambiente de trabalho}

Quando comparada com todas as outras competências do instrumento de pesquisa, a competência organização do ambiente de trabalho foi a que demonstrou maiores frequências de atribuições assinaladas, independentemente do vínculo com o SUS. A maioria das atribuições que compõem a competência estudada não ultrapassou $10 \%$ de diferença entre os índices de frequências encontrados nas respostas em cada grupo SUS e Não SUS.

A atribuição desse escopo de competência em que os índices encontrados mais se diferenciaram entre os grupos foi a que se referiu a 'controlar o movimento financeiro'. Apenas 4,2\% dos trabalhadores do SUS disseram realizar essa atribuição; em compensação, 40,9\% dos que não trabalham no SUS afirmaram ser uma responsabilidade de sua competência. Esse resultado discrepante que apresentou o estudo remete à reflexão sobre as marcantes diferenças que compõem os saberes e práticas dos trabalhadores quando se consideram os diferentes âmbitos público e privado (Tabela 2).

Quanto à 'utilização de recursos de informática', mesmo que em grau menor, também se destacou a vantagem na frequência de respostas para os trabalhadores que não eram do SUS - 51,1\% compreenderam como atribuição dentro do seu escopo de competência, em relação a apenas 38,9\% dos que atuavam no SUS (Tabela 2).

\section{Atendimento clínico em saúde bucal}

Com relação à competência de atendimento clínico em saúde bucal, observou-se que foram as atribuições de 'manipular materiais de uso odontológico' e 'instrumentar os profissionais nas intervenções clínicas' as mais referidas por ambos os grupos, atingindo índices em torno de $80 \%$. Os resultados do estudo a respeito da competência marcaram diferenças entre as atribuições clínicas nos grupos de profissionais SUS e não SUS estudados. No grupo SUS de trabalhadores, foi menos frequente a resposta sobre 'processar o filme radiográfico', 'confeccionar modelos de gesso', 'realizar tomadas radiográficas' e 'realizar moldagens'. Já os trabalhadores que não eram do SUS responderam com menos frequência com relação às atribuições 'realizar controle de placa bacteriana' (Tabela 2). 


\section{Considerações finais}

A análise dos resultados do estudo permitiu três conclusões. Primeiramente, que as diferenças marcantes no processo de trabalho dos auxiliares e técnicos de saúde bucal determinadas pelo vínculo de trabalho ao SUS concentram-se no desenvolvimento das atribuições relacionadas às competências de promoção e prevenção de saúde. Os profissionais que atuam no SUS trabalham não só mais intensamente com as competências do campo como também apresentam uma distribuição mais equitativa de realização das atribuições que compõem as competências no campo.

Em segundo lugar, pôde-se concluir pelos resultados apresentados no artigo que foi o grupo de atribuições pertencentes à competência de organização do ambiente de trabalho que conferiu maior aproximação e identificação entre os processos de trabalho dos auxiliares e técnicos com e sem vínculo com o SUS.

O terceiro resultado significativo que o estudo apontou foi que não há diferenças expressivas entre o processo de trabalho realizado pelos auxiliares de saúde bucal e aquele desenvolvido pelos técnicos de saúde bucal, independentemente do vínculo. Verificou-se que as competências e atribuições assinaladas pelos auxiliares também foram relatadas pelos técnicos, resultando em número pequeno de atribuições exclusivas a esses últimos.

A discussão e a análise dos resultados apresentados pelo artigo permitiram observar que o papel desempenhado pelos auxiliares e técnicos ainda está muito aquém do que se espera serem suas potencialidades, e que a inovação não está marcando a evolução de suas competências e atribuições profissionais. Parece que a lei n. 11.889 não está sendo um instrumento legal com capacidade de estimular a promoção da ampliação das competências e atribuições desses trabalhadores.

Concluiu-se que uma mudança do status profissional dos trabalhadores auxiliares e técnicos de saúde bucal para a odontologia tem sido muito difícil de se realizar. A profissão como um todo deve perceber que essas mudanças precisam ser assumidas como algo positivo e que ampliam o perfil da prática odontológica. Mas isso depende também de investimentos futuros em pesquisas abordando a compreensão em profundidade sobre a contribuição desses trabalhadores para o agir profissional no cuidado da saúde bucal. 


\section{Colaboradores}

Cristine Maria Warmling e Evelise Klein da Rosa realizaram a concepção do estudo, a pesquisa de campo e organizaram o banco de dados. Ramona Fernanda Ceriotti Toassi também organizou o banco de dados. As três autoras citadas e Luciane Maria Pezzatto colaboraram na revisão de literatura, interpretação dos achados, redação, revisão e aprovação do texto final. A primeira autora realizou o desenho inicial do artigo.

Resumen El estudio tuvo por objetivo describir el perfil sociodemográfico, de trabajo y de formación de auxiliares y técnicos en salud bucal con actuación en el estado de Río Grande do Sul, Brasil. Se analizó la información relatada por 255 auxiliares y técnicos de salud bucal, que participaron en el Congreso Riograndense de Odontología, realizado en 2010 y 2012. La investigación fue realizada por medio de un cuestionario escrito, estructurado y autoaplicable, organizado en tres bloques temáticos con las siguientes categorías: identificación (sexo, edad, estado civil, estado/ciudad, ingresos, habilitación, vínculo e inscripción consejo/sindicato), formación (establecimiento, duración, incentivos/dificultades de actualización/formación) y proceso de trabajo (competencias y atribuciones profesionales). Los resultados demostraron que diferencias en el proceso de trabajo entre auxiliares y técnicos de salud bucal, determinadas por el vínculo laboral con el Sistema Único de Salud, estaban concentradas en las atribuciones de competencias de promoción y prevención de la salud. Además, se constató que las atribuciones de competencias de organización del ambiente de trabajo y de atención clínica de salud bucal proporcionan mayor identidad al trabajo de estos profesionales, independiente del vínculo. El estudio alerta sobre la superposición de competencias y atribuciones realizadas por auxiliares y técnicos de salud bucal.

Palabras clave salud bucal; competencia profesional; recursos humanos; salud de la familia.

\section{Notas}

1 Universidade Federal do Rio Grande do Sul, Faculdade de Odontologia, Programa Pós-Graduação em Ensino na Saúde, Faculdade de Medicina, Porto Alegre, Rio Grande do Sul, Brasil.

<cristinewarmling@yahoo.com.br>

Correspondência: Rua Dona Leonor, 194/1.407, CEP 90420-180, Porto Alegre, Rio Grande do Sul, Brasil.

2 Hospital Nossa Senhora da Conceição, Porto Alegre, Rio Grande do Sul, Brasil.

$<$ evesocial@hotmail.com>

3 Universidade Federal de São Paulo, Departamento de Saúde, Clínica e Instituições, Santos, São Paulo, Brasil.

<lupezzato@yahoo.com.br> 
4 Universidade Federal do Rio Grande do Sul, Faculdade de Odontologia, Programa Pós-Graduação em Ensino na Saúde, Faculdade de Medicina, Porto Alegre, Rio Grande do Sul, Brasil.

<ramona.fernanda@ufrgs.br>

\section{Referências}

ADAMS, Tracey L. Inter-professional conflict and professionalization: dentistry and dental hygiene in Ontario. Social Science and Medicine, Oxford, v. 58, p. 2.243-2.252, 2004.

BONAN, Paulo R. F. et al. Perfil de técnicos em higiene dental quanto à prática profissional, à educação permanente e ao trabalho em serviço público. Revista Odonto Ciência, Porto Alegre, v. 24, n. 2, p. 180-185, 2009.

BRASIL. Ministério do Trabalho e Emprego. Classificação Brasileira de Ocupações. 2002. Disponível em: <www.mtecbo.gov.br/cbosite/ pages/home.jsf $>$. Acesso em: 14 jun. 2014.

BRASIL. Ministério da Saúde. Perfil de competências profissionais do técnico em higiene dental e do auxiliar de consultório dentário. Brasília: Ministério da Saúde, 2004a. (Série A. Normas e Manuais Técnicos).

BRASIL. Ministério da Saúde. Secretaria de Atenção à Saúde. Departamento de Atenção Básica. Coordenação Nacional de Saúde Bucal. Diretrizes da Política Nacional de Saúde Bucal. Brasília: Ministério da Saúde, 2004b. Disponível em: <http://bvsms.saude.gov.br/ bvs/publicacoes/politica_nacional_brasil_ sorridente.pdf>. Acesso em: 16 fev. 2016.

BRASIL. Lei n. 11.889, de 24 de dezembro de 2008. Regulamenta o exercício das profissões de técnico em saúde bucal (TSB) e de auxiliar em saúde bucal (ASB), 2008. Disponível em: <www.planalto.gov.br/ccivil_03/ _Ato2007-2010/2008/Lei/L1 1889.htm>. Acesso em: 14 jun. 2014.
CARVALHO, Cristiana L. Trabalho e profissionalização das categorias auxiliares em odontologia. In: BRASIL. Ministério da Saúde. Guia curricular para formação do atendente de consultório dentário para atuar na Rede Básica do SUS. v. 2. Área curricular IV, texto n. 5. Brasília: Ministério da Saúde, 1998.

\section{CONSELHO FEDERAL DE ODONTOLOGIA.} Resolução n. 85 de 2009. Altera as redações do inciso II do artigo 121 e dos capítulos IV e V da Consolidação das Normas para Procedimentos nos Conselhos de Odontologia, 2009. Disponível em: <http://cfo.org.br/ ato-normativo-pop.php?id=1286>. Acesso em: 16 fev. 2016.

CONSELHO FEDERAL DE ODONTOLOGIA. Cadastro de profissionais. 2014. Disponível em: <http://cfo.org.br/servicos-e-consultas/ dados-estatisticos>. Acesso em: 14 jun. 2014.

ESPOSTI, Carolina D. D. et al. O processo de trabalho do técnico em saúde bucal e suas relações com a equipe de saúde bucal na Região Metropolitana da Grande Vitória, Espírito Santo, Brasil. Saúde e Sociedade, São Paulo, v. 21, n. 2, p. 372-385, jun. 2012.

FRAZÃO, Paulo. A participação do pessoal auxiliar odontológico na promoção da saúde bucal. Revista de Odontologia da Universidade de São Paulo, Bauru, v. 12, n. 4, p. 329-336, out.-dez. 1998.

FRAZÃo, Paulo. Sistemas de trabalho de alta cobertura na assistência odontológica na perspectiva do Sistema Único de Saúde. 
In: ARAÚJO, Maria E. (org). Odontologia em saúde coletiva. São Paulo: Faculdade de Odontologia da Universidade de São Paulo, 1999. p. 100-118.

FRAZÃO, Paulo; NARVAI, Paulo C. Lei n. 11.889/2008: avanço ou retrocesso nas competências do técnico em saúde bucal? Trabalho, Educação e Saúde, Rio de Janeiro, v. 9, n. 1, p. 107-121, mar.-jun. 2011.

GIBBONS, David E.; CORRIGAN, Mairead; NEWTON, Jonathan T. A national survey of dental hygienists: working patterns and job satisfaction. British Dental Journal, London, v. 190, n. 4, p. 207-210, Feb. 2001.

HANSEN, Leda M. M. Atendentes de consultório dentário: interações entre formação, prática e condições de trabalho. 110f. Dissertação (Mestrado em Odontologia Social) Universidade Federal do Rio Grande do Norte, Natal, 2002.

JOHNSON, Patricia M. International profiles of dental hygiene 1987 to 2006: a 21-nation comparative study. International Journal of Dental Hygiene, Oxford, v. 59, n. 2, p. 63-77, 2009.

KOVALESKI, Douglas F.; BOING, Antonio F.; FREITAS, Sérgio F. T. Recursos humanos auxiliares em saúde bucal: retomando a temática. Revista de Odontologia da Unesp, Marília, v. 34, n. 4, p. 161-165, 2005.

LIÑAN, Márcia B. G. Manual do Trabalho e Formação do ACD e THD. São Paulo: Editora Santos, 2009.

LIÑAN, Márcia B. G; BRUNO, Lúcia E. N. B. Trabalho e formação profissional do atendente de consultório dentário e do técnico em higiene dental. Trabalho, Educação e Saúde, Rio de Janeiro, v. 5, n. 2, p. 297-316, 2007.

LUCIAK-DONSBERGER, Claudia; EATON, Kenneth A. Dental hygienists in Europe: trends towards harmonization of education and practice since 2003. International Journal of Dental Hygiene, Oxford, v. 7, n. 4, p. 273-284, 2009.
MACHADO, Zita C. A qualificação profissional do técnico em higiene dental no Paraná: de estratégia de organização e democratização dos serviços público de saúde bucal ao ajuste conservador no âmbito do neoliberalismo. 213f. Dissertação (Mestrado em Educação) - Universidade Federal do Paraná, Curitiba, 1999.

MORITA, Maria C.; HADDAD, Ana E.; ARAÚJO, Maria E. Perfil do cirurgião-dentista brasileiro. Maringá: Dental Press, 2010.

NARVAI, Paulo C. Em defesa do técnico em saúde bucal. Divulgação em Saúde para Debate, Londrina, n. 6, p. 27-34, out. 1991.

NARVAI, Paulo C. Recursos humanos para a promoção da saúde bucal: promoção de saúde bucal. In: KRIGER, Léo (org.). Promoção de saúde bucal. São Paulo: Aboprev, Artes Médicas, 1997. p. 449-463.

NASH, David A. et al. Dental therapists: a global perspective. International Dental Journal, London, v. 58, n. 2, p. 61-70, Apr. 2008.

OLIVEIRA, José A. A. O técnico de higiene bucal: trajetória e tendências de profissionalização com vista ao maior acesso aos serviços de saúde bucal. 169f. Dissertação (Mestrado em Ciências na Área de Saúde Pública) Rio de Janeiro, Escola Nacional de Saúde Pública Sergio Arouca/Fundação Oswaldo Cruz, Rio de Janeiro, 2007.

OLIVEIRA, Beatriz A. et al. Conhecimentos e atitudes dos profissionais auxiliares de odontologia com relação aos fatores de risco para câncer de boca. Odontologia e Sociedade, São Paulo, v. 11, n. 1, p. 18-23, 2009.

PARANHOS, Luiz R. et al. Análise da relação entre o cirurgião-dentista e o pessoal auxiliar. Revista Odonto Ciência, Porto Alegre, v. 23, n. 4, p. 365-370, 2008.

PEZZATO, Luciane M.; COCCO, Maria I. M. O técnico em higiene dental e o atendente de consultório dentário no mundo do trabalho. Saúde em Debate, Londrina, v. 28, p. 212-219, 2004. 
PEZZATO, Luciane M.; COCO, Maria I. M.; BAGNATO, Maria H. S. O processo de formação do técnico em higiene dental e do atendente de consultório dentário no Brasil: uma história silenciada. Odontologia e Sociedade, São Paulo, v. 9, n. 1, p. 39-49, 2007.

PEZZATO, Luciane M. O processo de formação do técnico em higiene dental e do atendente de consultório dentário no Brasil: uma história silenciada. 200f. Dissertação (Mestrado em Educação) - Universidade Estadual de Campinas, Campinas, 2001.

QUELUZ, Dagmar P. Perfil dos profissionais auxiliares da odontologia e suas implicações no mercado de trabalho. Revista Odonto Ciência, Porto Alegre, v. 20, n. 49, p. 270-280, jul.-set. 2005.

RAMOS, Marise N. A pedagogia das competências: autonomia ou adaptação? 4. ed. São Paulo: Cortez, 2011.

RIBEIRO, Eliza S.; FISCHER, Geraldo E.; MARQUES, Mônica C. M. Perfil do técnico em higiene dental em Minas Gerais. Revista do CROMG, Belo Horizonte, v. 5, n. 3, p. 164-171, set.-dez. 1999.

ROSS, Margaret K.; IBBETSON, Raymond J. Education needs and employment status of Scottish dental technicians. British Dental Journal, London, v. 199, n. 2, p. 97-101, July 2005.

ROSS, Margaret K.; IBBETSON, Raymond J.; RENNIE, James S. Educational needs and employment status of Scottish dental hygienists. British Dental Journal, London, v. 198, n. 2, p. 105-109, Jan. 2005.

ROSS, Margaret K.; IBBETSON, Raymond J.; TURNER, Steve. Activity and education of clinical dental technicians: a UK survey. British Dental Journal, London, v. 203, n. 10, p. E22; discussion 592-593, November 2007.
SÁ, Eliana M. O. Quando o currículo faz a diferença...: o currículo integrado na formação em serviço do técnico em higiene dental (THD). 178f. Dissertação (Mestrado em Educação) - Pontifícia Universidade Católica de Minas Gerais, Belo Horizonte, 2000.

SANGLARD-OLIVEIRA, Carla A. Atribuições dos técnicos em saúde bucal na Estratégia Saúde da Família do estado de Minas Gerais. 99f. Dissertação (Mestrado em Mestre em Odontologia) - Universidade Federal de Minas Gerais, Belo Horizonte, 2011.

SANGLARD-OLIVEIRA, Carla A. et al. Exploring professionalization among Brazilian oral health technicians. Human Resources for Health, London, v. 10, n. 5, p. 1-10, 2012.

SBRAVATI, Richard S.; MENEGHIN, Marcelo C.; PEREIRA, Antônio C. THD no mercado de trabalho: uma nova realidade? ROBRAC, Goiânia, v. 8, n. 25, p. 37-39, 1999.

WARMLING, Cristine M.; MARZOLA, Norma R.; BOTAZZO, Carlos. Da autonomia da boca: práticas curriculares e identidade profissional na emergência do ensino da odontologia brasileiro. História, Ciências, Saúde-Manguinhos, Rio de Janeiro, v. 19, n. 1, p. 181-195, 2012.

ZANETTI, Carlos H. G.; OLIVEIRA, José A. A.; MENDONÇA, Maria H. M. Divisão do trabalho odontológico em perspectiva: desafio de interpretar as competências dos técnicos. Trabalho, Educação e Saúde, Rio de Janeiro, v. 10, n. 2, p. 195-222, jul.-out. 2012.

Recebido em 16/10/2013

Aprovado em 19/06/2014 